Maria Cecília de Souza Minayo 1

Suely Ferreira Deslandes 2

\title{
A complexidade das relações entre drogas, álcool e violência
}

\author{
The complexity of relations between drugs, \\ alcohol, and violence
}

1 Vice-Presidência de Ambiente, Comunicação e Informação, Fundação Oswaldo Cruz. Av. Brasil 4.365, Rio de Janeiro, RJ 21045-900, Brasil.

2 Instituto Fernades Figueiras, Fundação Oswaldo Cruz. Av. Rui Barbosa 716, 5o andar, Rio de Janeiro, RJ 22250-020, Brasil. desland@iff.fiocruz.br

\begin{abstract}
This article discuss the complex relations between drugs and viol ence. Drawing on empirical studies and current forms of discourse, it analyzes conceptual and methodological problems related to the establishment of causal nexuses, risks, and associations. By demonstrating the theoretical and practical difficulties in such associations, it also points to the need for a debate in the field of public health and social policies. The article expresses concern that programs and prevention not be contaminated by fallacies, contributing nothing to an understanding of (or action related to) the social issue of drugs.

Key words Street Drugs; Alcohol Drinking; Violence; Public Heal th; Sociology
\end{abstract}

Resumo Este artigo discute as complexas relações existentes entre drogas e violência. Valendose de al guns estudos com base empírica e dos discursos correntes, anal isa os problemas conceituais e metodológi cos rel aci onados ao estabel ecimento de nexos causais, ri scos e associ ações. Ao demonstrar as difi culdades teóri cas e práti cas destas del imitações, aponta também para um debate necessário no campo da saú de pública e das políticas sociais. Preocupa-se com que as intervenções e a prevenção não se contaminem por falácias, que em nada ajudam a compreensão ea ação relativas à problemática social das drogas.

Palavras-chave Drogas Ilícitas; Consumo de Bebidas Alcoólicas; Violência; Saúde Pública; Sociologia 


\section{Introdução}

Neste artigo, buscaremos levantar questões metodológicas para a investigação, a prevenção e a intervenção da saúde pública na articulação entre drogas e violência. Trata-se de uma articulação complexa, pouco analisada, cujos únicos parâmetros para afirmações, na atualidade, são apenas os de associação empírica. E é com base em alguns dados empíricos que levantaremos os problemas interpretativos diante desse tema desafiador para cientistas sociais, politicólogos, criminólogos e cidadãos militantes.

Como a maioria dos estudiosos, consideramos que há muita mistificação em torno da questão das drogas, exercendo ao mesmo tempo fascínio e provocando medo. Isso fica evidente em vários trabal hos, como os de Bastos (1995); Garcia (1996); Musa (1996) e outros que mostram os efeitos paradoxais das drogas, capazes de proporcionar desde êxtases prazerosos a estados de depressão, de viabilizar a inserção em grupos sociais e de conduzir a situações de exclusão social.

Neste trabalho, partimos de alguns pressupostos que consideramos importantes para discutirmos a questão. Assim, iniciamos nossa reflexão alertando para a necessidade de se considerar: a) a diferença entre dependência e uso recreacional e ocasional; (b) o erro de apontar o usuário como um dependente potencial; (c) as diferenças entre os vários tipos de drogas e os danos que provocam, como é o caso da maconha, cocaína, cocaína injetável, heroína, crack e outras; (d) o entendimento do uso de drogas como um fenômeno históricocultural com implicações médicas, políticas, religiosas e econômicas; (e) a distinção entre drogas legais e ilegais e o aparecimento de substâncias sintéticas.

Da mesma forma, no contexto da saúde, sabe-se que a violência social, em virtude de suas conseqüências, enquadra-se na categoria Causas Externas (códigos: E-800 a E-999 na 9a Revisão e V01 a Y98 na 10a Revisão), no sistema de Classificação Internacional das Doenças (CID); tal categoria abrange uma longa lista de eventos que podem ser resumidos como homicídios, suicídios e acidentes em geral. Compreende-se que essa classificação nem de longe consegue dar conta da dimensão e complexidade da violência, um fenômeno polissêmico, de explicação contraditória, mas permite trabalhar com indicadores capazes de informar e subsi diar ações políticas e sociais.

Em relação ao tema das interações entre violência e drogas, neste trabal ho apresenta- mos: (a) alguns dados empíricos; (b) discussão atual sobre mudanças resultantes do uso dessas substâncias nas funções cognitivas, nos estados emocionais, nas alterações hormonais e fisiológicas que podem motivar a violência; (c) discussão do mercado de drogas ilegais e o aumento da violência; (d) problemas interpretativos e de método de investigação.

\section{Alguns dados empíricos}

Os primeiros dados apresentados foram retirados de uma pesquisa ainda inédita (Deslandes, 1997) do Centro Latino-Americano de Estudos sobre Violência e Saúde - Jorge Careli (Claves/ Ensp/Fiocruz), realizada nos Hospitais Miguel Couto (HMMC) e Salgado Filho (HMSF), a qual teve como um dos objetivos caracterizar o peso da violência no atendimento da emergência hospitalar. Em vista da pergunta feita ao paciente ou socorrista: “O evento (violento) envolveu o uso de drogas?", os dados permitiram vislumbrar que: dos 2.736 atendimentos por todas as causas externas realizados em maio de 1996 no Miguel Couto, 343 (13\%) envolveram o uso de drogas. No Salgado Filho, de 2.192 atendimentos ocorridos em junho de 1996, 295 $(12,6 \%)$ tiveram alguma droga relacionada à sua ocorrência.

Nos casos em que foi identificado o consumo de algum tipo de droga, o álcool configurou-se como o mais freqüentemente consumido: $88 \%$ (HMSF) e $90,7 \%$ (HMMC). O consumo de álcool associado com outras drogas (cocaína, maconha e outros) foi declarado em 3,2\% dos casos no Miguel Couto e em 0,7\% dos casos no Salgado Filho.

Das 176 agressões atendidas no HMMC, $33 \%$ envolveram o uso de drogas; no HMSF, das 188 agressões, 37\% tiveram essa relação. Tais dados apontam para o fato de que uma em cada três agressões envolveu o consumo de drogas.

Nos casos de acidentes de trânsito (colisões e outros acidentes entre veículos automotores), situações em que são precárias as informações sobre a questão, 149 (HM M C) e 143 (HMSF), $40,5 \%$ e $33 \%$ respectivamente, envolveram o uso de drogas. Quanto aos atropelamentos, dos 158 atendidos no Miguel Couto, em 22,8\% houve a presença do consumo de alguma droga, o mesmo ocorrendo com os 143 (16,4\%) socorridos no Salgado Filho.

Obviamente, os dados aqui expostos devem ser relativizados. Correspondem a uma forma de expressão (emergência hospitalar) e a apenas um mês de rotina. 
Cherpitel (1993, 1994), em revisão bibliográfica, cita diferentes estudos em emergências hospitalares americanas os quais comprovam que, das vítimas de agressão, $43 \%$ a $51 \%$ delas tinham o teste de Blood Alcohol Concentration (BAC) positivo. O autor também elenca 11 estudos que compararam grupos de pacientes atendidos por evento violento com grupos atendidos por outros motivos. Os resultados indicam que as vítimas de violências têm probabilidade de duas a cinco vezes maior de terem o teste de BAC positivo do que as vítimas de outras causas.

McGinnis \& Foege (1993) citam estudos onde se comprova que $40 \%$ a $50 \%$ das mortes ocorridas por acidentes de trânsito nos EEUU em 1990 tiveram o álcool como fator associado.

Ampliando o espectro microrregional, estudos de Yunes \& Rajs (1994) mostram que, na América Latina, a prevalência do consumo de cocaína varia de $1,4 \%$ a $6,7 \%$ na população de 12 a 45 anos. Além disso, entre grupos socialmente marginalizados, o consumo de inalantes é de 3\% a 4\%. Andrade (1995) cita pesquisa feita em 1993 com estudantes de dez capitais brasileiras, a qual aponta que $17,8 \%$ destes jovens reconheciam ter consumido drogas ilegais ou psicotrópicos ao menos uma vez na vida. Contudo, uma única experiência não conduz ao abuso, o uso de drogas é socialmente aprendido e grupalmente mediado (Becker, 1990). Todos esses dados, porém, exigem aprofundamento específico e diferenciado para serem mais bem compreendidos.

Drogas e mudanças bio-psico-sociais que possibilitam a violência: por um enfoque mais amplo das condutas individuais

As observações teóricas que seguem têm como referencial os trabalhos de Fagan $(1990,1993)$ e de Goldstein (1985, 1989), ambos preocupados com o fenômeno em pauta, sua conceitualização e prevenção.

Enquanto os especialistas concordam que drogas e álcool freqüentemente têm papel importante nas atividades violentas (OPAS, 1993, 1994; Yunes \& Rajs, 1994), seu papel específico não está claro, ou seja, é difícil de se determinar com precisão: (a) o nexo causal entre essas substâncias e atos violentos; (b) o status legal das drogas e as complicações envolvendo tráfico e leis que o reprimem; (c) as influências do meio e as características individuais dos usuários de drogas e álcool; (d) a prevalência e as correlações precisas entre violência e uso dessas substâncias. Este estudos mostram como é bastante complexa a construção de paradigmas para investigação nessa área.

Em relação ao primeiro ponto de discussão, vários estudiosos têm concluído que o álcool é a substância mais ligada às mudanças de comportamento provocadas por efeitos psicofarmacológicos que têm como resultante a violência. E isso, pelo menos provisoriamente, pode ser depreendido dos dados apresentados acima. Estudos experimentais (Fagan, 1990, 1993) mostram que o abuso de álcool pode ser responsável pelo aumento da agressividade entre os usuários. Há evidências também de que a cocaína, os barbitúricos, as anfetaminas e os esteróides têm propriedades que podem motivar atitudes, comportamentos e ações violentas. Por exemplo, os usuários de cocaína têm problemas de supressão de atividades neurotransmissoras, podendo ser vítimas de depressão, paranóia e irritabilidade (Goldstein, 1989; Musa, 1996). Fatores como peso corporal, tipo de metabolismo, processos neuroendócrinos e neuroanatômicos produzem diferenças individuais no uso de drogas e mudança de comportamento.

No entanto, apesar de evidências empíricas, há muita incerteza quanto às explicações causais. Uma questão que não está suficientemente explicada é se a presença de álcool ou drogas nos eventos violentos permite inferir que elas tenham afetado o comportamento das pessoas envolvidas. Noutras palavras, não é possível saber se essas pessoas em estado de abstinência não teriam cometido as mesmas transgressões. Outra questão é o não-discernimento entre o uso de drogas como um fator que, associado a outros, desencadeia comportamentos violentos e o uso de drogas como fator causador, porque, na verdade apenas o que nos é possível inferir é a alta proporção de atos violentos quando o álcool ou as drogas estão presentes entre os agressores e vítimas, ou em ambas as partes.

Uma terceira questão vem do fato de que enquanto o álcool e as drogas podem ser causa de, resposta a, ou mediadores de uma diversidade de comportamentos sociais violentos, pouco se sabe das contribuições dessas substâncias na vitimização. Por exemplo, os usuários dependentes, uma vez que estão sob condições sociais de estigmatização, podem acabar por desenvolver comportamentos mais agressivos (Boyum \& Kleiman, 1995). Por outro lado, quase todas as pesquisas enfatizam o agressor e não a vítima. Poucos estudos analisam o envolvimento com álcool ou drogas por parte das vítimas. Wolfang (1958), num estudo sobre o perfil dos homicídios nos EEUU, cu- 
nhou uma expressão "vítima precipitante" para caracterizar a situação em que a vítima provocou primeiro o agressor; o autor notou que, em tais casos, encontrou-se grande quantidade de álcool no sangue delas. Outros pesquisadores, como Coid (1986), mostram que o álcool altera a percepção das interações sociais, aumentando os riscos de desentendimentos para os participantes nessa situação.

A questão causal torna-se ainda mais complexa quando se trata de relações de gênero. Por exemplo, Collins \& Messerschimdt (1993), numa pesquisa sobre o assunto, concluíram que as mulheres vítimas de homicídios usavam menos drogas e álcool do que os homens. $\mathrm{O}$ uso de álcool pelo homem (e não de drogas em geral) apresentou-se como um significativo fator de risco para a violência entre marido e muIher, contudo o uso por mulheres não foi detectado como um fator de risco nas relações de violência entre parceiros. Por outro lado, o uso de drogas ou álcool pela vítima não apareceu como um fator de risco para a violência sexual, nem dos homens em relação às mulheres, ou vice-versa. Da mesma forma, as baixas taxas de participação das mulheres em roubo e outros comportamentos violentos não podem ser explicadas apenas por diferenças de gênero ou menor ingesta de álcool e drogas.

Outro ponto a considerar é que a variabilidade dos efeitos provocados por cada tipo de substância sugerem a contribuição de fatores sócio-culturais e de personalidade. A violência tem mais chances de ser exercida em determinados segmentos, locais e situações específicos, sob condições específicas. Alguns bares têm mais brigas que outros, algumas comunidades e até al guns casais com mesmo padrão de uso de álcool ou drogas são mais violentos que outros, assim como as pessoas com um mesmo grau de intoxicação têm respostas emocionais diferentes. Essas complexidades sugerem que a violência interpessoal que ocorre sob o efeito de substâncias é contextualizada, ou seja, acontece em locais específicos, sob normas e regras específicas de determinados grupos e diante de expectativas que al imentam e são alimentadas dentro desses grupos. Para encontrar nexo causal entre determinadas substâncias e violência seria necessário saber se os comportamentos e atitudes violentas ocorreriam ou não no interior desses segmentos, caso a droga e o álcool não estivessem presentes. As evidências empíricas sugerem que drogas ilícitas e álcool desempenham importante papel nos contextos onde são usados, porém sua importância fica em grande medida dependente de fatores individuais, sociais e culturais.
Drogas ilegais, mercado e violência

Embora todas as evidências empíricas revelem que é o álcool a substância mais significativa na articulação com várias formas de violência, seu status de legalidade torna-o socialmente aceito e largamente consumido, ainda que se tente regular seu uso. Tal questão revela a inconsistência da definição de 'droga' e como tal, o conceito é historicamente datado e apoiado em valores discutíveis (McRae, 1994). Vale lembrar que, nas situações históricas em que o uso do álcool foi proibido, a maioria das condições de estigmatização e violência também estiveram presentes nas relações de seu mercado ilegal.

Uma das mais costumeiras associações entre drogas e violência num contexto de mercado ilegal é a chamada 'motivação econômica' de usuários dependentes. Nesses casos, o crime é visto como uma fonte de recursos para a compra de drogas, geralmente cocaína, crack e heroína. Contudo, estudo americano (Boyum \& Kleiman, 1995) demonstra que, de todos os presidiários usuários freqüentes de cocaína e crack, somente 39\% declararam ter cometido crime para a compra de droga, o que também pode ser uma espécie de defesa para minimizar a responsabilidade dos atos cometidos. Percebe-se que a motivação econômica é uma explicação apenas parcial do complexo universo que constitui o mercado de drogas.

O mais consistente e predizível vínculo entre violência e drogas se encontra no fenômeno do tráfico de drogas ilegais. Este tipo de mercado gera ações violentas entre vendedores e compradores sob uma quantidade enorme de pretextos e circunstâncias: roubo do dinheiro ou da própria droga, disputas em relação a sua qualidade ou quantidade, desacordo de preço, disputa de territórios, de tal forma que a violência se torna uma estratégia para disciplinar o mercado e os subordinados.

O narcotráfico potencializa e torna mais complexo o repertório das ações violentas: a delinqüência organizada; aquela agenciada pela polícia e pelas instituições de segurança do estado; a violência social dispersa; a promovida por grupos de extermínio e também a das gangs juvenis.

Na medida em que não há recursos legais para dirimir as disputas, a violência ou a ameaça de violência são mecanismos para reforçar as regras sociais de troca no mercado ilícito. No Brasil, o crime organizado floresceu e se institucionalizou a partir da década de 80, espaIhando o medo, aumentando as estatísticas de homicídios, e tornando-se uma verdadeira res- 
posta social, como mercado de trabal ho, sobretudo para os jovens pobres das periferias e favelas, sem expectativas de conseguir emprego formal, e que, então, na ilegalidade, buscam saciar seus sonhos de consumo, status e reconhecimento social. Tomando-se um exemplo dos EEUU dos anos 20 e 30, sabe-se que a Máfia recrutava seus adeptos entre os jovens (homens) de 18 a 25 anos, crianças e imigrantes que viviam nos bairros pobres. Esse grupo de risco continuou a ser o preferido pelos narcotraficantes nas duas últimas décadas. Jovens, pobres de favelas e periferias urbanas, tornaram-se força de trabalho preferencial para o tráfico e, uma vez integrados neste mercado, participam de uma série de relações de reciprocidade social onde favores recebidos e retribuídos são regidos por rígido controle do grupo, a ponto de tornar-se quase impossível a saída espontânea de um membro (Zaluar, 1993). Este grupo é selecionado dentro de um contexto em si violento, com promessas de ganhos fáceis e imediatos, numa situação de escassez de opções do mercado formal.

Desta forma, ao mesmo tempo em que a situação de violência e drogas reflete a questão do status legal das substâncias, reflete também as chances e oportunidades que a economia formal deixa de oferecer, circunstância sob a qual o mercado das drogas floresce. Por outro lado, o mercado formal apenas aparentemente não compartilha do comércio ilegal de drogas, pois é de domínio público o envolvimento, em redes nacionais e internacionais, de instituições políticas, financeiras e empresariais com o capital gerado e em circulação proveniente dessa peculiar fonte de riqueza. O comércio ilegal também está muitas vezes ligado ao tráfico de armas, misturando-se constantemente a negócios oficiais de importação e exportação (Velho, 1994).

O simples fato de ser legal o acesso ao álcool e ilegal em relação a outras drogas, torna difícil estabelecer os tipos de condições necessárias para isolar os efeitos das substâncias específicas ou de indivíduos e grupos específicos. Por outro lado, como Sá (1994) revela, o Brasil adota uma política de criminalização de certas drogas, associando-se a visão jurídica ('caso de polícia') a uma perspectiva médico-psiquiátrica ('doença mental'). Esta política se auto-reproduz ideologicamente (a imagem do uso de drogas como crime cria socialmente a figura do criminoso) e materialmente (o sistema produz uma realidade conforme a imagem da qual surge e a legitima).

O estudo de Bastos (1995) mapeia muito bem as dificuldades que a sociedade tem para refletir sem preconceitos a questão das drogas, para aceitar a lógica das comunidades dos usuários e entender seu significado na sociedade. Velho (1994) ressalta a importância de se estudarem os valores presentes nas subculturas ligadas ao uso de drogas ilícitas e enfatiza que estes laços e comportamentos unicamente se tornam anti-sociais e violentos num contexto de severa marginalização. Zaluar (1993, 1994) ressalta o percurso dos jovens dependentes (sobretudo os mais pobres) que sofrem múltiplas exclusões: na família, escola, vizinhança, até finalmente serem perseguidos pela polícia como criminosos. A autora alerta que a criminalização, enquanto tentativa de controlar o mercado pela lei, além de não ser medida eficaz, tornou este mercado imune a qualquer forma de controle exterior. Neste processo, a prática de violências atrozes e incontroláveis medeiam e expressam estas relações, favorecendo um imaginário social do 'mal absoluto', fora da medida humana e de seu controle.

\section{Obstáculos para a interpretação}

Muitos eventos de bebedeira ou de uso de drogas não são suficientes para se concluir pela sua articulação direta com a violência. No entanto, o álcool está associado à perpetração de $50 \%$ de todos os homicídios, mais de $30 \%$ dos suicídios e tentativas de suicídio, e à grande maioria dos acidentes de trânsito, conforme dados da OPAS (1993). Enquanto, porém, muitos poderiam apressadamente concluir pela relação causal entre drogas e violência, as taxas de homicídios são bem baixas se comparadas com as de prevalência de uso de álcool ou drogas.

Isso nos desafia em dois sentidos. O primeiro é que, se em muitos eventos violentos, encontra-se alguma associação com o uso de drogas ou álcool, não se pode afirmar peremptoriamente que inevitavelmente isso aconteça ou que esta relação seja de causalidade. Em segundo lugar, trata-se de uma falácia ecológica a idéia de que substâncias ilegais e pobreza, por exemplo, são responsáveis por eventos violentos. Essa idéia parte de um determinismo biológico, social e econômico. Por exemplo, se é verdade que existe uma relação entre altas taxas de violência e uso de drogas em determinados bairros pobres, há grandes diferenças de taxas entre bairros com a mesma situação sócio-econômica estrutural. Desta forma, há necessidade de se reconhecer a complexidade do contexto social, da dinâmica das comunidades e das normas culturais historicamente cons- 
truídas e dos fatores de personalidade e individualidade.

No entanto, negar a linearidade das influências ecológicas não significa cair no outro extremo, que reconhece apenas as diferenças individuais como explicativas pelo abuso de substâncias e pela sua articulação com a violência. A falácia individualista sugere que há conexão entre intoxicação por drogas e agressão física como resultado de personalidade, respostas endócrinas, neuroanatômicas ou outros fatores individuais. Essa argumentação despreza o contexto estrutural, cultural esituacional. Por exemplo, a literatura sobre violência doméstica, violência das gangs de jovens, mostra situações culturais problemáticas que o uso de drogas pode acirrar ou não, mas não as consegue explicar.

Há várias dificuldades em se medir a relação entre violência e drogas. A correlação entre uso de substância e violência varia se nós buscamos medir comportamentos ou efeitos. A correlação de freqüência entre drogas e violência doméstica varia se medirmos eventos graves ou freqüência de agravos. Do ponto de vista metodológico, as definições operacionais influenciam nos resultados das pesquisas. Em alguns estudos, ganha-se na compreensão da magnitude do problema; em outros, busca-se a sua especificidade, perdendo-se a extensão.

Drogas e álcool tanto podem ser usados antes como depois dos eventos violentos. Muitas vezes as substâncias são utilizadas como desculpas para violência, para diminuir a responsabilidade pessoal. Outros as usam para simplesmente atingirem um estado emocional que Ihes facilite cometer crimes. Há aqueles que consideram o comportamento de beber ou usar drogas como parte da interação grupal. Muitos, ainda, corroborando a análise de Freud em O Mal-Estar da Civilização, usam drogas para suportar as agruras da vida, como mostram também os estudos de Bastos (1995) e Garcia (1996). Ou seja, ambos, álcool e drogas em si, dizem pouco enquanto fatores de risco para a violência, e essa articulação merece ser mais investigada, melhor delineada, buscando-se exatamente conhecimentos e práticas que contribuam para a saúde da população.

Por fim, as fontes de dados têm interesses intrínsecos. A fidedignidade das informações dos usuários depende da preocupação que têm com a utilização que se fará de seus relatos. As informações oficiais estão influenciadas por variáveis organizacionais. As informações dos estudiosos levam a diferentes resultados de acordo com as referências conceituais, bases de dados e com os agregados populacionais. As informações das vítimas são diferentes daquelas recolhidas com os agressores.

Hoje, o caminho que parece mais correto é analisar o que realmente acontece quando há um evento violento e são usadas drogas. Isso incluiria o esclarecimento dos motivos e intenções, conhecer as seqüências e interações que redundaram em violência, bem como dados dos acontecimentos que precederam e sucederam o fato em questão.

\section{Propostas de parâmetros para intervenção e prevenção}

Como se pode concluir, é muito complexo o fenômeno da violência e sua articulação com as drogas, exigindo que seja tratado com instrumentos, conhecimentos e ações que ultrapassem a mera representação ou o moralismo simplista.

A atuação dos grupos comunitários em relação ao uso de substâncias e violência sugere que o contexto cultural modera e regula intoxicações e ações violentas. Os segmentos e o contexto influenciam a escolha de substâncias, comportamentos e normas, interpretação da situação e a probabilidade de acontecerem agressões. É preciso tomar o contexto em consideração, sobretudo quando se trata de situações de alto risco. A análise de eventos deve focalizar conseqüências das interações comportamentais, interações entre substância e pessoa, interações entre pessoas e pessoas, além da quantidade de drogas ou álcool consumidos e o tempo de uso.

As ações produzidas visando à prevenção precisam ser elaboradas incluindo as comunidades e suas instituições, os diversos setores públicos (Educação, Saúde e Justiça), as empresas e os meios de comunicação de massa (OSAP, 1991). Posturas, habilidades e alternativas de lazer podem ser categorias trabalhadas em ações de prevenção. Tais ações devem ser elaboradas levando-se em conta o contexto a que se destinam e questões fundamentais, como o grupo etário, gênero, características individuais, situação social, tipo de comunidade e participação em grupos específicos. Uma atitude de 'escuta', aberta às vivências dos grupos e apoiada numa perspectiva pedagógica centrada no respeito e atenta às peculiaridades sócio-culturais são elementos muito importantes. Sem dúvida, as ações de prevenção ao abuso de drogas só alcançarão real efetividade se houver um investimento significativo e de qualidade na educação básica, na melhoria das 
condições de vida, na oferta de emprego sobretudo para jovens de comunidades mais pobres, no reforço cultural de valores que desfavoreçam a drogadição abusiva e na val orização do diálogo e apoio familiar.

A perspectiva de atuação, seja apoiada na visão de redução de danos, seja na abordagem da prevenção primária (MS, 1997), precisa ser respaldada pelo debate entre cientistas sociais e cientistas naturais, entre organizações não governamentais e representantes das secretarias e coordenações de programas de saúde e de outros setores da ação pública, ultrapassando preceitos normativistas da conduta dos indivíduos e preconceitos sociais.

Por outro lado, programas de apoio e tratamento àqueles já dependentes devem ser incentivados, disseminados, descentralizados e tecnicamente apoiados pela Saúde Pública e outras áreas competentes. Tais projetos precisam estar apoiados numa perspectiva de respeito à identidade e cidadania do paciente. $\mathrm{O}$ atendimento a estes usuários dependentes não pode deixar de lado seus direitos como pessoa e sujeito. Entende-se que programas de apoio seriam mais eficazes se acompanhados de trabalho visando mudar as relações entre usuários dependentes, sua família e comunidade. Sá (1994) alerta para o fato de que os principais problemas enfrentados pelos usuários não são decorrentes do uso da substância, mas aqueles frutos da marginalização.

É preciso, principalmente, pensar e repensar social e politicamente toda a rede de negócios que faz das drogas um assunto criminoso como um dos maiores fatores, hoje, de incremento da violência social.

O desafio para a saúde pública, que hoje se preocupa tanto com o uso abusivo de drogas, quanto com a violência, como fatores de risco para a qualidade de vida, é conseguir um quadro referencial para a reflexão e para a ação que inclua ao mesmo tempo o individual, o social e o ecológico.

\section{Referências}

ANDRADE, A. G., 1995. As drogas mais usadas no Brasil e suas conseqüências. In: Drogas, Aids e Sociedade (Programa Nacional de DST/AIDS, ed.), pp. 53-59, Brasília: Ministério da Saúde/Programa Nacional de DST/AIDS.

BASTOS, F. J., 1995. Ruína e Reconstrução, AIDS e Drogas Injetáveis na Cena Contemporânea. Rio de Janeiro: Relume-Dumará.

BECKER, H., 1990. How to become a marijuana user. In: Simbolic Interaction (J. Manis \& B. Meltzer, eds.), pp. 411-422, Boston: Allyn \& Bacon.

BOYUM, D. \& KLEIM AN, M. A. R., 1995. Alcohol and other drugs. In: Crime (D. Boyum \& M. A. R. Kleiman, eds.), pp. 295-326, California: Institute for Contemporary Studies Press.

CHERPITEL, C. J., 1993. Alcohol and violence-related injuries: an emergency room studies. Addiction, 88:79-88.

CHERPITEL, C. J., 1994. Alcohol and injuries resulting from violence: a review of emergency room studies. Addiction, 89:157-165.

COID, J., 1986. Alcohol, rape and sexual assault. In: Alcohol and Aggression (P. F. Brain, org.), pp. 161183, London: Croom Helm.

COLLINS, J. \& MESSERSCHIMDT, P., 1993. Epidemiology of alcohol-related violence. Alcohol, Health and Research World, 17:93-100
DESLANDES, S. F., 1997. O Impacto da Violência nos Serviços de Emergência: Estudo em Hospitais Municipais do Rio de Janei ro (HMMC e HMSF, 19951996). Rio de Janeiro: Centro Latino-Americano de Estudos sobre Violência e Saúde - Jorge Careli, Departamento de Ciências Sociais, Escola Nacional de Saúde Pública, Fundação Oswaldo Cruz. (mimeo.)

FAGAN, J., 1990. Intoxication and aggression. In: Drugs and Crime (M. Tonry \& J. Q. Wilson, eds.), pp. 8-43, Chicago: Chicago University Press.

FAGAN, J., 1993. Drugs, alcohol and violence. Health Affairs, 12:66-79.

GARCIA, S. J., 1996. Implicações Psi cossociais do Uso deDrogas. Dissertação de Mestrado, Rio de Janeiro: Escola Nacional de Saúde Pública, Fundação Oswaldo Cruz.

GOLDSTEIN, P., 1989. Crack and homicide in New York City, 1988. A conceptually-based event analysis. Contemporary Drugs Problems, 16: 651-687.

GOLDSTEIN, P., 1985. The drugs-violence nexus: a tri-partite conceptual framework. Journal of Drugs Issues, 15:493-506.

MS (Ministério da Saúde), 1997. Diretrizes para Projetos de Redução de Danos. Documento Preliminar. Brasília: Ministério da Saúde/ Programa Nacional de DST/AIDS. (mimeo.) 
McGINNIS, J. M. \& FOEGE, W. H., 1993. Actual causes of death in the United States. Journal of American Medical Association, 270:2.207-2.212.

MCRAE, E., 1994. A importância dos fatores socioculturais na compreensão das drogas. In: Drogas e Cidadania (A. Zaluar, org.), pp. 31-46, São Paulo: Brasiliense.

MUSA, G., 1996. Alcoolismo e Drogadição na Adolescência. Tese de Doutorado, Ribeirão Preto: Faculdade de Medicina, Universidade de São Paulo.

OPAS (Organização Panamericana de Saúde), 1993. Resolución XIX: Violência y Salud. Washington: OPAS. (mimeo.)

OPAS (Organização Panamericana de Saúde), 1994. Salud y Violencia:Plan de Acción Regional. Washington: OPAS. (mimeo.)

OSAP (Office for Substance Abuse Prevention), 1991. Prevention Pluss III - Assessing Al cohol and Other Drugs Prevention Programs at School and Community Level. Atlanta: US Department of Health and Human Services.
SÁ, D. B. S., 1994. Projeto para uma nova política de drogas no País. In: Drogas e Cidadania (A. Zaluar, org.), pp. 147-171, São Paulo: Brasiliense.

VELHO, G., 1994. A dimensão cultural e política dos mundos das drogas. In: Drogas e Cidadania (A. Zaluar, org.), pp. 23-29, São Paulo: Brasiliense.

WOLFGANG, M., 1958. Patterns of Criminal Homicide. Philadelphia: University of Pennsylvania Press.

YUNES, J. \& RAJS, D., 1994. Mortalidad por causas violentas. Cadernos de Saúde Pública, 10 (supl. 1):88-125.

ZALUAR, A., 1993. A criminalização de drogas e o reencantamento do mal. Revista do Rio deJaneiro, 1:8-15.

ZALUAR, A., 1994. Introdução. In: Drogas eCidadania (A. Zaluar, org.), pp. 7-21, São Paulo: Brasiliense. 